- The notion of 'attitudes' is more complex than many people realise

- Attitudes are an important feature of professional life

- There are several methods of teaching attitudes

- There is a rich variety of methods of assessing attitudes

- Attitudes in dentistry are too important not to be assessed

\title{
Assessing attitudes in dental education: Is it worthwhile?
}

\author{
G. Brown, ${ }^{1}$ M. Manogue ${ }^{2}$ and M. Rohlin ${ }^{3}$
}

\begin{abstract}
An exploration is undertaken of the issues surrounding the assessment of attitudes in undergraduate dental programmes with a view to considering whether such an assessment is worthwhile. This paper addresses five questions: What are attitudes?; Why focus on them?; Can they be changed?; Can they be taught?; and How can they be assessed? The evidence and supporting arguments indicate that attitudes may be defined; there are cogent reasons for assessing them; they do change and they are taught; it is possible to assess them. The assessment of attitudes is not only worthwhile, it is essential.
\end{abstract}

The General Dental Council of the United Kingdom has recently produced a revised version of 'The First Five Years' in which they recommend that dental schools include attitudinal objectives in their degree programmes so that students acquire and demonstrate a prescribed set of professional attitudes by the time they graduate (see Table 1). ${ }^{1}$ These attitudinal objectives include attitudes to learning, personal development, inter-professional and dentist-patient relationships, professional responsibilities and ethical issues. The recommendations of the GDC are laudable but they raise questions such as 'What are attitudes?', 'Why focus on them?', 'Can they be changed?', 'Can they be taught?' and 'How can they be assessed?'. All these questions are related to the subject of this paper.

${ }^{1}$ Special Professor of Education, c/o Postgraduate Dental Office, Queen's Medical Centre, Nottingham NG7 2UH;

$2^{*}$ Dean for Learning and Teaching, Faculty of Medicine, Dentistry, Psychology and Health, University of Leeds, Leeds LS2 9LU; ${ }^{3}$ Professor of Oral Radiology, Faculty of Odontology, Malmö University, Carl Gustavs väg 34, S- 214 21 Malmö, Sweden

${ }^{*}$ Correspondence to: Michael Manogue

E-mail:m.manogue@leeds.ac.uk

\section{Refereed Paper}

Received 09.04.02; Accepted 13.08.02

๑ British Dental Journal 2002; 193: 703-707
One needs to have a clear idea of what is being assessed and why. If attitudes cannot be changed, there is little point in assessing them, except perhaps, at the point of entry to dental school or to the profession. In other words, there would be little point in attempting to teach or assess attitudes during undergraduate or postgraduate courses. In this paper we discuss these issues with a view to considering whether the assessment of attitudes is, in fact, worthwhile in dental education.

\section{WHAT ARE ATTITUDES?}

The term 'attitude' originally meant a physical posture or stance. It is now used to describe a mental posture or stance towards objects, people, processes or institutions. Attitudes cover a range of terms from core personality traits/values to an outer orbit of mood swings and opinions. ${ }^{2}$ There is no such thing as an attitude per se, rather an attitude always has an object (such as 'patients', 'problem-based learning, 'continuing professional development', 'the Dental Practice Board').

Values are core attitudes. These include broad orientations such as respect for individuals, freedom to learn, professional ethics and self-fulfilment. Core attitudes may link together sub-sets of attitudes to provide the base for judgements and actions. The closer attitudes are to personality traits, the less amenable they are to change. $^{3}$

Definitions of attitudes depend upon the theoretical orientation of the authors who define them. They have been described as mental scaffolds ${ }^{4}$ that influence a person's actual or potential actions. ${ }^{2}$ An all-encompassing, but commonly held view of attitudes was that they contained three components: cognitive (knowledge and understanding), affective (emotions and feelings) and behavioural (practical and social skills) components. ${ }^{5}$ A rough and ready description of attitudes that the current authors favour is that an attitude is a mixture of beliefs, thoughts and feelings that predispose a person to respond, in a positive or negative way, to objects, people, processes or institutions. The description implies that personality factors and "world views' $^{2}$ as well as contexts influence attitudes. For a person to have an attitude towards something, he or she must have some active knowledge and understanding (however misplaced) and have made a judgement. $^{3}$ All of these features shape beliefs and feelings. The strength of feeling may vary from mild to strong. For example, dentists may not have strong feelings about the need for use of rubber dam in endodontics, despite knowledge of its benefits (thus 
Table 1. Extracts from The First Five Years Draft Revised Edition. General Dental Council 2001 pp 9-10 (1st draft)

\section{THE UNDERGRADUATE CURRICULUM MUST:}

- Promote acquisition of the skills and professional attitudes and behaviour that facilitate effective and appropriate interaction with patients and colleagues;

- Encourage recognition and acceptance of the obligation to practise in the best interest of patients at all times, as outlined in the GDC's guidance on professional and personal conduct in Maintaining Standards;

- Foster the knowledge and understanding, attitudes and skills that will promote effective lifelong learning and support professional development.

\section{ATTITUDINAL OBJECTIVES}

The dental graduate should have:

- Approaches to teaching and learning that are based on curiosity and exploration of knowledge rather than its passive acquisition.

- A desire for intellectual rigour, a capacity for self-audit and the need to participate in peer review.

- An awareness of personal limitations, a willingness to seek help as necessary, an ability to work effectively as a team member.

- Respect for patients and colleagues that encompasses without prejudice diversity of background and opportunity, language and culture.

- An understanding of patient rights, particularly with regard to confidentiality and informed consent.

- An awareness of moral and ethical responsibilities in the provision of care to individual patients and to populations.

- An appreciation of the importance of honesty and trustworthiness.

- An understanding of audit and clinical governance.

- An awareness that dentists should strive to provide the highest possible quality of patient care at all times.

- An awareness of the importance of the trainee's own health and its impact upon his or her ability to practise as a dentist.

- An awareness of the need for continuing professional development allied to the process of their continuing education to ensure that high levels of clinical competence and knowledge are maintained.

affecting level of use) but they may have strong feelings about University/hospital car parking (so affecting their attendance at postgraduate courses).

Figure 1 sets out a simple heuristic model which shows the possible links between attitudes, cognition, skills and outcomes. The implication of this model is that one can attempt to work directly on attitudes or seek to change them indirectly by changing levels of knowledge and understanding. However, the model also reveals that attitudes are but one of the predispositions to act, so it is difficult to separate the measurement of attitudes from the measurement of other predispositions. Attitudes are inferred from behaviour, but this inference assumes that observed behaviour is the outcome largely of the attitude in question. In practice, the correlation between attitudes and behaviours are not always high. ${ }^{6-8}$ To complicate matters further, there may be conflicting attitudes at play. For example, an individual may have a positive attitude towards the National Health Service (NHS) but a negative attitude towards the current wave of administrative procedures within the NHS. This conflict can produce a tension which, according to Festinger's theory of cognitive dissonance $^{9,10}$ is resolved by behaviour which results in a shift toward one of the conflicting attitudes. In other words, changes in behaviour can result in changes in attitudes. Other, more sophisticated models of influences upon behaviour are available. ${ }^{10,11}$ For example, Ajzen ${ }^{11}$ argues that there is an intermediary intention to act between attitudes and actual behaviour. It is only when this intention is sufficiently strong that attitudes shape behaviour.

Despite the range of theories of how attitudes influence behaviour, there remains the lay belief that attitudes are merely a shorthand summary of past actions which may be used to predict future actions. Unfortunately, this approach does not explain how, when and where attitudes are likely to trigger behaviours. But whatever one's personal theories, inferring atti-

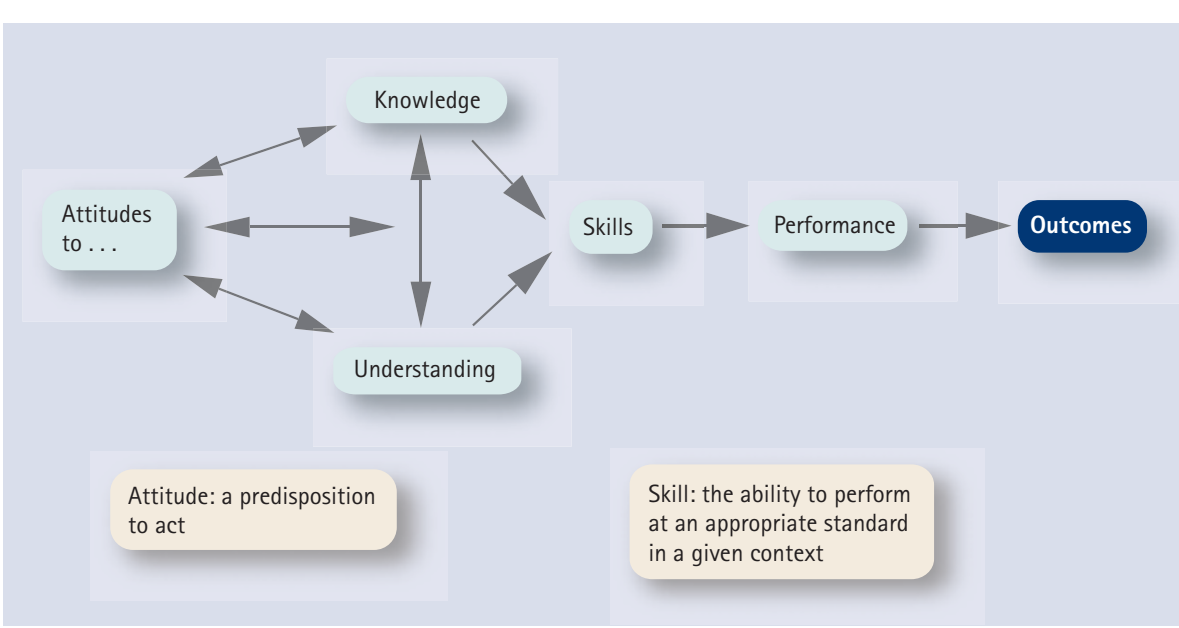

Fig. 1 Attitudes and skills tudes from behaviours is a complex business. It requires careful attention to:

- The operational definition of the attitudes being measured

- The sample of behaviours taken

- The contexts in which they are taken

- The methods and criteria of assessment used

- The underlying assumptions of the methods and criteria.

\section{WHY FOCUS ON ATTITUDES?}

There are several reasons for focusing on attitudes. Notable amongst these are to:

- Ensure dental students and dentists are safe professionals

- Help dental students and dentists to develop their professional expertise from the first year of the undergraduate programme

- Change attitudes

- Estimate that change

- Improve interpersonal relationships;

- Change contexts and organisations (for example, the ways in which attitudes affect the working of dental practices and university dental hospitals)

- Satisfy demands of accountability and control.

Each of these reasons could be worthy of a paper in itself and each requires a different emphasis in content and approach. Renewed interest in attitudes has been brought about by rising public expectations of health care, ${ }^{12}$ concerns about failure in professional training ${ }^{13}$ and sensationalised media coverage of unprofessional practices. In a study of success and failure in professional education, based on syndicate groups in Sweden and the United Kingdom, unprofessional behaviour (which could be described as a product of attitudes), was the most frequently reported reason for failing students. ${ }^{14}$ This finding is mirrored in the report of Donaldson on major problems amongst senior consultants. ${ }^{15}$ Unprofessional practices are part 
of what has been described as "moral deficiencies' to which all health care professionals are prone. ${ }^{16}$ They are not necessarily transgressions of duties (negligence) but they may pervade a dentist's approach to patient care. They include:

\section{- Paternalism}

- Not taking the patient's concerns seriously

- Lacking an attitude of compassion

Other inadequacies may exist in the relationship between dentists and their staff and in the attitude of a dentist to his or her own professional development. All of these are addressed in the list of attitudinal objectives of the GDC. ${ }^{1}$ However, one should be wary of assuming that these problems will be minimised if the 'correct' attitudes are taught in dental schools. Such a view underestimates the potency of the contexts in which dentists work and overestimates the capability of dental schools to change permanently the attitudes of all their students.

There are other issues underlying the current focus on attitudes in dentistry. First, what attitudes should be assessed and what attitudes should not be assessed? Some people regard attitudes as a private matter and assessing attitudes as a form of social control. Arguments about this issue abound in sociology. ${ }^{17}$ What are regarded as appropriate attitudes in dentistry change over time. Few dentists today would advocate extraction of all teeth except when absolutely necessary; cross-infection control is now highly regarded; hostile attitudes to women in dentistry are no longer acceptable. But what about disrespect for the National Health Service? Who should decide which attitudes to assess and how to assess them? Which attitudes held by undergraduates or practising dentists should lead to failure or being struck off the dental register? For example, should students fail because they do not conform to a strict dress code in the clinic? Should students fail because they disagree with a tutor about the best form of treatment for a patient? Should practising dentists be struck off because they will not treat immigrants who refuse local anaesthetics? All of these issues and many more are pertinent to the measurement of attitudes in dentistry.

\section{CAN ATTITUDES BE CHANGED?}

It would be curious if attitudes could not be changed. Indeed, dental education is predicated upon the assumption that students can develop into professionals. Much of that professionalisation involves development of attitudes. By setting explicit attitudinal objectives, the GDC assumes that attitudes may be acquired, demonstrated and, therefore, changed. Their view is supported by a wealth of evidence from social psychology on attitude change. ${ }^{2,3,5}$ Attitudes may be changed through:

- Personal experience (direct contact with patients and dental teachers)

- Reflection on personal experience

- Group interaction

- Group membership

- Professional identity

- Chance conditioning (stray remarks such as 'God, not another left-hander')

- Media influences (persuasion)

- Cult influences (closed communities)

There seems to be little evidence on attitude change in dentistry although the importance of assessing attitudes is now recognized. ${ }^{18}$ Evidence from studies in medical education show that students do change in attitudes as the programme progresses although personality traits stay constant. These traits include high need for achievement, dominance, autonomy, order and endurance, and low need for impulsivity and play. ${ }^{19}$ Unfortunately, some of the changes in attitudes are in the direction of cynicism and a decrease in humanistic values. ${ }^{19-22}$

In summary, three points should be borne in mind when considering whether attitudes may be changed. Firstly, attitudes are, in varying degrees, resistant to change (otherwise we would all be in a state of instability); secondly, attitudes can be changed (otherwise we would never develop), but a change in a person's attitude does not necessarily lead to a change in behaviour (other attitudes, predispositions, motives, emotions (feelings), or habits may be more potent); thirdly, core attitudes are less amenable to change than peripheral attitudes. This lattermost finding might lead some policy makers to advocate that attitude inventories should be used to select students for dental school so that those with 'unfavourable' attitudes could be filtered out. The difficulty would be finding an appropriate attitude inventory which is better than existing selection procedures. Very few dental students become rogue dentists and there is no guarantee that the use of inventories would work and indeed, they might filter out potentially able dentists who are capable of developing professional attitudes during a course. Selection is only part of the problem. It is probably as important to assess attitudes during an undergraduate programme, at the point of graduation and in the early stages of a dentist's professional career. Such a view has implications for undergraduate and postgraduate teachers and for vocational trainers.

\section{CAN ATTITUDES BE TAUGHT?}

The above discussion underpins the importance of asking oneself a question often asked in workshops on attitudes: 'Can attitudes be taught?'. The simple answer is that attitudes are already taught, directly and indirectly, in dental education. Current curricula develop scientific attitudes, sometimes at the expense of humanistic values. ${ }^{23-25}$ The introduction of the study of, for example, English Literature in medical programmes is designed to provide a counterbalance to purely scientific approaches ${ }^{26-28}$ and similar courses could be introduced into UK dental programmes. The evidence suggests that favourable attitudes towards lifelong learning and continuing professional development are more likely to be developed in PBL curricula and other innovative schools. ${ }^{29,30}$ Attitudes may be changed through collaborative small group teaching, they are likely to be changed by collaborative learning ${ }^{31}$ and they may be changed by the use of reflective portfolios ${ }^{32,33}$ although the latter may run the risk of becoming bureaucratic exercises. Attitudes may also be changed through conventional methods of teaching but the danger is that students will merely memorise and recite the 'correct' attitudes learnt from lectures, rather than necessarily changing their behaviour.

At a more abstract level, changes in attitudes could be deliberately brought about in dental education by working directly on beliefs, thoughts and, perhaps, feelings. Indirectly, it is plausible that attitudes may be changed by increasing knowledge, deepening understanding and improving levels of technical and communicative competence (see Figure 1). Case-based, small group teaching on ethical and professional issues have their place here. However, perhaps the most powerful influences on attitudes are those of the 'hidden curriculum: ${ }^{25,34-36}$ This might be described as the unintended consequences of the structure of a programme, the teaching and attitudes of its teachers and its methods of assessment. An implication of the studies of the 'hidden' curriculum is that students learn through role-modelling so tutors need to be aware of their own behaviour and to be vigilant in their observations of student behaviour in pre-clinical as well as clinical courses. Even the unintentional remarks of a tutor may have an effect upon a student's attitudes. This form of 'chance conditioning' is perhaps more common than is realised.

\section{HOW CAN ATTITUDES BE ASSESSED?}

Assessing attitudes is more a matter of professional judgement than of measurement, although judgements may be converted into scores on a test or inventory. Three main approaches can be used to assess attitudes in 
dental education: direct observation, conventional methods of assessment and selfreports.

\section{Direct observation}

One can assess attitudes through direct observation or observation of video-recordings. The usual rules apply: trained observers, the use of simple, explicit criteria and an adequate sample of behaviours. At the University of Toronto, attitudes have been assessed at Ethics Stations in OSCEs. ${ }^{37}$ Students have consultations with simulated patients which raise practical ethical issues. The performance is assessed against a standard checklist. From these results, attitudes are inferred. In this method, one assumes that the clinical behaviour of a student, or his or her report, is an expression of attitudes as well as of knowledge.

Extensions of direct observations are the use of reports on clinical attachments. ${ }^{38}$ Assessment should be based on the application of explicit criteria concerned with professional attitudes at the end of the attachment either by the consultant, if he or she has seen the student at work, or the dental team. Students who receive adverse reports could be required to take remedial action, but in many current curricula, little time is available for such flexibility of approach.

All of these approaches are relatively close to the clinical situation but they present the problems of observer error and of performance changing in the presence of others. However, it could be argued that these approaches are the most relevant since ultimately one is interested in future professional behaviour rather than underlying attitudes. Such a view assumes that because a student does the right thing under examination conditions then he or she will do the right thing in future situations. Arguably, knowledge and deep understanding are necessary if the behaviours are likely to persist and transfer to new situations. ${ }^{39}$ Similar remarks apply to clinical examinations at all levels of dental education.

\section{Conventional methods}

There is a rich variety of methods of assessment ${ }^{39,40}$ and almost all of these could be used to assess attitudes. The standard methods of written and oral tests such as essays, short answer questions, modified essay questions, case-based MCQs, vignettes, 'unseen' cases and orals can be used to measure the range of attitudinal objectives provided by the GDC. Case studies, portfolios, reflective practice assignments, audits of practice and qualitative-based projects are particularly useful for developing and assessing formatively attitudes but the methods do require trust between a student and her or his tutor. However, none of these methods measure directly 'observable' behaviour with patients or colleagues. What they can measure is knowledge of 'right' behaviour, as defined by the attitudinal objectives, so one has an indication that students do know the 'correct' way to behave.

Of the above methods, vignettes are perhaps the least known. These consist of a set of written cases in which are embedded ethical or professional issues. Students are required to answer a set of questions involving identification of key issues and decisions. The method is useful for formative and diagnostic purposes. In the 'Professional and Decisions Value Test' ${ }^{41}$ the themes are: obligation to the patient versus society; respect for patient autonomy versus professional responsibility; protecting the patient's interest versus respect for authority. In the 'Medical Ethics Inventory' 42 students are asked to rate the importance of six value statements that follow each vignette. Other vignettes require students to give their opinions on the issues involved. These are assessed against a 'gold standard' developed by consensus of the examiners. ${ }^{43}$ Vignettes may be used in other forms. Such approaches include tests of memory, based on the supposition that what is recalled is affected by one's attitudes, and information tests where, it is assumed, that in cases of uncertainty, people will tend to guess an answer in the direction of their attitudes. ${ }^{44}$

All of the above methods are potentially useful but, as with all methods of assessment, they need to be matched to learning objectives, to have appropriate content and clearly defined, user-friendly, criteria.

\section{Self-report measures}

Self-report measures include questionnaires based on specific issues, attitudinal objectives or more generalised attitude or personality inventories. Carefully designed questionnaires are useful for assessing the attitudes of a group, particularly if the respondents remain anonymous. They can be useful in purely formative assessments but if they become part of the final assessment then the students' answers might, again, become a repetition of acceptable views rather than an honest expression of attitudes.

The 'Doctor-Patient Scale'45,46 and the 'Norton Scale' ${ }^{\text {'77 }}$ on doctor-patient communication could provide the basis for measuring attitudes to dentist-patient communication. Scales on more specific issues such as attitudes to the care of the elderly ${ }^{48}$ could be also be adapted for use in dentistry. All these scales have potential benefit for feedback to students on their attitudes but, as above, it would be unwise to use them as a basis for summative assess- ment. The TAD ('Totalitarian-Authoritarian-Dogmatism') scale ${ }^{49}$ attempts to measure antipathy towards patients and may, the authors suggest, identify aspects of the humanistic qualities proposed by the American Board of Internal Medicine. ${ }^{50}$ A second instrument which might be worth exploring experimentally, as a selection tool or for formative purposes, is the 'NEO Personality Inventory'(NEO-PI) ${ }^{51,52}$ which measures Neuroticism, Extroversion, Openness, Agreeableness and Conscientiousness.

Which methods of assessment should one use? Two somewhat conflicting rules of thumb apply. First, the more remote the method is from the clinical situation, the less likely will it assess specific attitudes or attitudinal objectives. The second is the most reliable methods are usually those that are remote from clinical situations, such as personality or attitude inventories. In practice, one may have to sacrifice some reliability for validity and practicality. However, the reliability, validity and practicality of a method is determined by the specific content of the method used rather than the method per se. A well-designed questionnaire is better than a poor set of observations.

\section{ASSESSING ATTITUDES: IS IT WORTHWHILE?}

To return to the central question of this paper: Is assessing attitudes worthwhile? The short answer is a cautious 'yes'. Attitudes and the purposes of assessing attitudes may be broadly defined and attitudinal objectives can be stated sufficiently clearly for them to be assessed. Attitudes may be changed and they are already taught directly and indirectly in dental schools - but one should be aware of the assumption that measures of attitudes are accurate predictors of future professional behaviour and know the limitations of the assessment methods used. However, attitudes are central to professional expertise and conduct: they are too important not to be assessed.

But it would be wrong to assume that assessment per se is enough. If we are really serious about the development of professional attitudes, we must also look carefully at the culture of dental schools, their curricula, the modes of teaching used and, perhaps most important of all, at the attitudes of dental teachers and practising dentists.

The authors would like to thank Dr Jonathan Martin for drawing our attention to some of the research on attitude scales and the anonymous referees for their helpful comments on the original manuscript.

General Dental Council. 'The First Five Years.' London: Revised Edition (draft), 2001.

2 Baron R A, Byrne D E. Social Psychology. New York: Allyn \& Bacon, 2000. 
3 Deaux K, Dane FC, Wrightsman L. S Social Psychology in the 90s. 6th ed. California: Brooks Cole, Pacific Grove, 1993.

4 Ajzen I, Fishbein M. Understanding Attitudes and Predicting Social Behavior. New Jersey: Prentice-Hall, 1980.

5 McGuire W J. Attitudes and Attitude Change. In Lindsey G, Artonson E (eds) Handbook of Social Psychology.3rd ed, Volume 2: pp 333-346. New York: RandomHouse, 1985.

6 La Piere R T. Attitudes versus actions. Social Forces 1934; 13: 230-237

7 Kaplan R M. Behaviour as the central outcome of health care. Am Psychologist 1990; 45: 1211-1220

8 Conner M, Norman P. Predicting health behaviour. Buckingham: Open University Press, 1995.

9 Festinger L. A Theory of Cognitive Dissonance. New York: Row, Peterson \& Company, 1957.

10 Ogden J. Health Psychology: A Textbook. Buckingham: Open University Press, 1996

11 Ajzen I. Attitudes, traits and actions: dispositional prediction of behaviour in personality and social psychology. Adv ExperiSoc Psychol 1987; 20: 1-63

12 MacNaughton J. Medicine and the arts: let's not forget the medicine. Br J Gen Prac 1998; 48: 952-953.

13 Ilott I, Murphy R. Success and Failure in Professional Education: Assessing the Evidence. London: Whurr Publishers, 1999.

15 Donaldson LJ. Doctors with problems in a NHS work force. Br Med J 1994; 308: 1277-1282.

16 Downie R S, Calman K C. Healthy Respect. Oxford, : Oxford University Press, 1994.

17 Aldridge A, Levine K. Surveying the Social World. Buckingham: Open University Press, 2002.

18 Mossey PA, Newton J P, Stirrups D R. Defining, conferring and assessing the skills of the dentist. BrDent J 1997; 182: 123-125

19 Rezler A G. Attitude changes during medical school: a review of the literature. JMed Edu 1974; 49:10231030.

20 Zeldow P B Daugherty S R. The stability and attitudinal correlates of warmth and caring in medical students. Med Educ 1987; 21:353-357.

21 Wolf T M, Balson P M, Faucett J M et al. A retrospective study of attitude change during medical education. Med Educ 1989; 23: 19-23.

22 Coles R. The moral education of medical students. Acad Med 1998; 73: 55-58.

23 Weatherall DJ. The inhumanity of medicine. BrMed J 1994; 309: 1671-1672.

24 Brown G, Rohlin M, Manogue M. Culture, Collegiality and Collaborative Learning. In: Hutley S, Sweet J (eds). Effective Learning and Teaching in Medical, Dental and Veterinary Education. London: Kogan Page (in press).

25 Cribb A, Bignold S. Towards the Reflexive Medical School: the hidden curriculum and medical education research. Studies Higher Educ 1999; 24: 195-209.

26 Pellegrino E D. Teaching medical ethics: some persistent questions and some responses. Acad Med 1989; 64: 701-703.

27. Calman K, Downie R. Why arts courses for medical curricula? The Lancet 1996; 347:1499-1500

28. Downie R S, Hendry R A, MacNaughton R J et al. Humanizing medicine: a special study module. Med Educ 1997; 31: 276-280.

29 Schmidt H G, Molen H T. Self-reported competency ratings of graduates of a problem-based medical curriculum. Acad Med 2001; 76: 466-468.

30 Coles C. The process of learning. In Jolly B, Rees L (eds). Medical Education in the Millennium. Oxford: Oxford University Press, 1998.

31 Jaques D. Learning in Groups. London: Kogan Page, 2000

32 Challis M. Portfolio-based learning and assessment in medical education. Med Teacher 1998; 21:370-386.

33 Friedman S, Ben-David M, Davis M H, Harden R M et al. Portfolios as a method of student assessment Med Teacher 2001; 23: 535-551.

34. Sinclair S. Making Doctors. Oxford: Berg, 1997

35. Maheux B, Beland F. Students' perceptions of values emphasized in three medical schools. J Med Educ 1986; 61: 308-316.

36 Hafferty FW, Franks R. The hidden curriculum, ethics teaching and the structure of medical education. Acad Med 1994; 69: 861-871.

37 Cohen $R$, Singer PA, Rothman A I et al. Assessing competency to address ethical issues in medicine.
Acad Med 1991; 66: 14-15.

38 Phelan S, Obenshain S S, Galey W R. Evaluation of the non-cognitive professional traits of medical students. Acad Med 1993; 68: 799-803.

39 Brown G, Bull J, Pendlebury M. Assessing Student Learning in Higher Education. London: Routledge, 1997.

40 http://www.Dented.org

41 Rezler A G, Schwartz S, Obenshain P et al. Assessment of ethical decisions and values. Med Educ 1992; 26: 7-16.

42 Stolman C J, Doran R L. Development and validation of a test instrument for assessing value preferences in medical ethics. J Med Educ 1982; 57: 170-179.

43 Hebert PC, Meslin E M, Dunn EV. Measuring the ethical sensitivity of medical students: a study at the University of Toronto. J Med Ethics 1992; 18: 142-147.

44 Rezler A G. Methods of assessment for medical teachers. Med Educ 1976; 10: 43-51.

45 Markert R J. Cross-cultural validation of the DoctorPatient scale. Acad Med 1989; 64: 80-83.

46. Batenburg V. Do professional attitudes change during medical education? Adv Health Sci Educ 1997; 1: 153-164.

47 McManus I C, Kidd J M, Aldous I R. Self-perception of communicative ability: evaluation of a questionnaire completed by medical students and general practitioners. Br J Health Psych 1997; 2: 301-315.

48 Beisecker A E, Murden R A, Moore W P et al.Attitudes of medical students and primary care physicians regarding input of older and younger patients in medical decisions. Med Care 1996; 34: 126-137.

49 Merrill J M, Boisaubin EV, Laux L etal. Measuring 'humanism' in medical residents. Southern Med J 1986; 79: 141-144.

50 American Board of Internal Medicine. Evaluation of Humanistic Qualities in the Internist. Annals Internal Med 1983: 99: 720-724.

51 Costa P T, McCrae R R, Dye D A. Facet scales for agreeableness and conscientiousness: a revision of the NEO personality inventory. Personality Individual Differences 1991; 12: 887-898.

52 Matthews G, Deary I J. Personality Traits. Cambridge: Cambridge University Press, 1998. 